\title{
Global carbon uptake by cement carbonation
}

Fengming Xi ${ }^{1,2,3}$, Steven J. Davis ${ }^{1,4}$, Philippe Ciais ${ }^{5}$, Douglas Crawford-Brown ${ }^{6}$, Dabo Guan $^{7}$, Claus Pade ${ }^{8}$, Tiemao Shi ${ }^{3}$, Mark Syddall ${ }^{6}$, Jie Lv ${ }^{9}$, Lanzhu Ji ${ }^{1}$, Longfei Bing ${ }^{1}$, Jiaoyue Wang ${ }^{1}$, Wei Wei ${ }^{10}$, Keun-Hyeok Yang ${ }^{11}$, Björn Lagerblad ${ }^{12}$, Isabel Galan ${ }^{13}$, Carmen Andrade ${ }^{14}$, Ying Zhang ${ }^{15}$, Zhu Liu ${ }^{16,17^{*}}$

${ }^{1}$ Institute of Applied Ecology, Chinese Academy of Sciences, Shenyang 110016, China

${ }^{2}$ Key Laboratory of Pollution Ecology and Environmental Engineering, Chinese Academy of Sciences, Shenyang 110016, China.

${ }^{3}$ College of Architecture and Urban Planning, Shenyang Jianzhu University, Shenyang 110168, China

${ }^{4}$ University of California, Irvine, Department of Earth System Science, Irvine, CA, 92697, USA

${ }^{5}$ Laboratoire des Sciences du Climat et de l'Environnement, CEA-CNRS-UVSQ, CE Orme des 14 Merisiers, 91191 Gif sur Yvette Cedex, France

${ }^{6}$ Cambridge Centre for Climate Change Mitigation Research, Department of Land Economy, University of Cambridge, 19 Silver Street, Cambridge CB3 9EP, UK

${ }^{7}$ School of International Development, University of East Anglia, Norwich NR4 7TJ, UK

${ }^{8}$ Danish Technological Institute, Gregersensvej, 2630 Taastrup, Denmark

${ }^{9}$ College of Economy and Management, Shenyang Agricultural University, Shenyang, 110000, China

${ }^{10}$ CAS Key Laboratory of Low-carbon Conversion Science and Engineering, Shanghai Advanced Research Institute, Chinese Academy of Sciences, Shanghai 201203, China

${ }^{11}$ Department of Plant Architectural Engineering, Kyonggi University, Gwanggyosan-ro 154-42, Yeongtong-gu, Suwon, Kyonggi-do 16227, South Korea

${ }^{12}$ Swedish Cement and Concrete Research Institute, CBI Betonginstitutet, SE-100 44, Stockholm, Sweden

${ }^{13}$ Department of Chemistry, University of Aberdeen, Aberdeen AB24 3UE, UK

${ }^{14}$ Eduardo Torroja Institute CSIC, Serrano Galvache 4, 28033 Madrid, Spain

${ }^{15}$ Shenyang Pharmaceutical University, Shenyang 110016, China

${ }^{16}$ Resnick Sustainability Institute, California Institute of Technology, Pasadena, California 91125, USA

${ }^{17}$ John F. Kennedy School of Government, Harvard University, Cambridge, Massachusetts 02138, USA

*Correspondence to: Zhu Liu (zhuliu@ @ caltech.edu). 
Calcination of carbonate rocks during the manufacture of cement produced $5 \%$ of global $\mathrm{CO}_{2}$ emissions from all industrial process and fossil-fuel combustion in $2013^{1,2}$. Considerable attention has been paid to quantifying these industrial process emissions from cement production ${ }^{2,3}$, but the natural reversal of the process - carbonation--has received little attention in carbon cycle studies. Here, we use new and existing data on cement materials during cement service life, demolition, and secondary use of concrete waste to estimate regional and global $\mathrm{CO}_{2}$ uptake between 1930 and 2013 using an analytical model describing carbonation chemistry. We find that carbonation of cement materials over their life cycle represents a large and growing net sink of $\mathrm{CO}_{2}$, increasing from 0.10 GtC $\mathrm{y}^{-1}$ in 1998 to $0.25 \mathrm{GtC}^{-1}$ in 2013. In total, we estimate that a cumulative amount of $4.5 \mathrm{GtC}$ has been sequestered in carbonating cement materials from 1930 to 2013, offsetting $43 \%$ of the $\mathrm{CO}_{2}$ emissions from production of cement over the same period, not including emissions associated with fossil use during cement production. We conclude that carbonation of cement products represents a substantial carbon sink that is not currently considered in emissions inventories $^{1,3,4}$. [190 words]

One Sentence Summary: Globally, carbonating cement materials are a large, overlooked and growing net sink of $\mathrm{CO}_{2}$, which has offset $43 \%$ of the total process $\mathrm{CO}_{2}$ emissions (excluding those from related fossil energy inputs) from production of cement between 1930 and 2013. 
A tremendous quantity of cement has been produced worldwide for the construction of buildings and infrastructure, namely: 76.2 billion tons of cement between 1930 and 2013, and 4.0 billion tons in 2013 alone ${ }^{1}$. When making cement, the high temperature calcination of carbonate minerals (e.g., limestone rocks) produces clinker (mainly calcium oxide), and $\mathrm{CO}_{2}$ is released into the atmosphere from this process. These "process" $\mathrm{CO}_{2}$ emissions from cement production (as opposed to related emissions from fossil fuel energy that may have been used during cement production) comprise approximately $90 \%$ of global $\mathrm{CO}_{2}$ emissions from all industrial processes and $5 \%$ of global $\mathrm{CO}_{2}$ emissions from industrial processes and burning fossil fuels combined ${ }^{2-4}$. Cumulative cement process emissions are estimated to have released $38.2 \mathrm{Gt} \mathrm{CO}_{2}$ from 1930 to $2013^{2-4}$.

However, the calcium oxide in cement materials is not stable over time and cement hydration products gradually re-absorb atmospheric $\mathrm{CO}_{2}$ through a physiochemical process called carbonation ${ }^{5-8}$. Carbonation occurs when $\mathrm{CO}_{2}$ diffuses into the pores of cement-based materials and reacts with hydrated products in the presence of pore water 8,9 (see Methods). The carbonation starts at the surface of the concrete or mortar and progressively moves inwards. Although carbonation reactions are known to civil engineers due to their effects on the strength and safety of structures ${ }^{5,10}$, the resulting large-scale $\mathrm{CO}_{2}$ uptake flux has not been quantified. In contrast to the instantaneous emissions of $\mathrm{CO}_{2}$ during manufacture of cements, carbonation is a slow process that takes place throughout the entire life cycle of cement-based materials ${ }^{5,11}$. The $\mathrm{CO}_{2}$ uptake through carbonation of cement materials is thus proportional to the time- 
integral of cement consumption. Previous studies have applied a life cycle assessment to estimate concrete carbon sequestration over 100-200-year time scales ${ }^{5,11,12}$. However, these studies were limited to concrete materials in specific regions, and did not account for $\mathrm{CO}_{2}$ uptake in other types of cement materials found in built infrastructure: cement mortar, construction cement waste, and cement kiln dust worldwide.

Based on new datasets compiled from field surveys in China and a comprehensive synthesis of existing data and studies (see Methods), we modeled the global atmospheric $\mathrm{CO}_{2}$ uptake by four different cement materials (concrete, mortar, construction cement waste, and cement kiln dust) between 1930 and 2013 in four regions (China, the U.S., Europe, and the rest of the world) and analyzed the sensitivity of our uptake estimates to 26 different variables (see Methods).

Details of our calculations are available in the Methods. In summary, carbon sequestration from concrete was calculated from three stages in the life cycle of this material: service life, demolition, and secondary use of concrete waste ${ }^{5}$ In each case, we estimated exposed surface areas ${ }^{5,10}$, thicknesses ${ }^{10,13}$, exposure conditions including atmospheric $\mathrm{CO}_{2}$ concentrations in different regions ${ }^{5,9,14,15}$, and exposure time $\mathrm{e}^{5,16-18}$ and modeled carbon uptake by applying Fick's diffusion law ${ }^{15}$ and concrete carbonation rate coefficients derived from both experimental measurements ${ }^{5,18,19}$ and an extensive review of relevant literature ${ }^{15,20}$. The effect of different concrete strength classes, exposure conditions, additions, and coatings were explicitly modeled $^{5}$. Exposure time in service life $(\mathrm{t})$ was assumed to be the average building 
lifetime, ranging from 35-70 years ${ }^{5,10-12}$, and carbon sequestration in demolition and secondary use stages was modeled assuming a spheric concrete shape for particles in waste $^{21}$, with carbonation fractions affected by waste concrete treatment methods, waste concrete particle size $\mathrm{e}^{13,22}$, and changing exposure conditions during phases of demolition and either reuse or disposal ${ }^{13}$. The carbon sequestration from mortar was calculated based on mortar utilization thickness ${ }^{23}$ and annual carbonation depth using the Fick's diffusion law. The carbon uptake from construction cement waste and cement kiln dust was estimated generation rate and carbonation fraction ${ }^{24,25}$. Model uncertainties and sensitivities to assumptions were evaluated by a Monte Carlo analysis that varies 26 individual parameters over 100,000 iterations (See Methods).

We find that a large fraction of global cement process $\mathrm{CO}_{2}$ emissions, both cumulatively and annually in recent years, are reabsorbed by carbonation of cement materials. Figure 1a shows the annual carbon sequestration by cement materials between 1930 and 2013 disaggregated by world region. Based on our uncertainty analysis, we find a mean estimated global carbon uptake by all cement materials was $0.24 \mathrm{Gt} \mathrm{C}(2 \sigma= \pm 10.0 \%)$ in 2013 . Prior to 1982 , the majority of sequestration occurred in Europe and the U.S., corresponding to the legacy carbon sink of cement building and infrastructure built during the 1940s and 1950s (Figs. 1a and 1c). Since 1994, cement materials used in China have absorbed more $\mathrm{CO}_{2}$ than the other regions combined due to its rapidly increasing cement production (Fig. 1a). Mortar cement consistently sequestered the most carbon, even though only $30 \%$ of cement is used in mortar (Fig. 1b). This is because mortar is frequently applied in thin decorative 
layers to the exterior of building structures, with higher exposure surface areas to atmospheric $\mathrm{CO}_{2}$ and thus higher carbonation rate coefficients (See Supplementary data $)^{23}$. Despite a relatively smaller exposure area and therefore lower carbonation rate coefficients, concrete cement is the second largest contributor to the carbon sink because $\sim 70 \%$ of all produced cement is used in concrete. Figure 1c shows the legacy effects of accumulating cement stocks; on average, between 2000 and 2013, 25.0\% of the carbon sequestered each year was absorbed by cement materials produced more than 5 years earlier and 14\% produced more than 10 years earlier. Demolition causes an increase in carbonation rates by exposing large and fresh surfaces. Because the average 35 -year service lifetime of structures in China ${ }^{16}$ is shorter than the average 65-70 years in the U.S. ${ }^{17}$ and Europe ${ }^{5}$, the turnover of cement with respect to carbonation has been increasing over time, accelerating the uptake of $\mathrm{CO}_{2}$ (Fig. 1c).

Figure 2 shows the net annual $\mathrm{CO}_{2}$ emissions related to industrial process of cement production minus the estimated annual $\mathrm{CO}_{2}$ sequestration from carbonation of cement materials. Between 1990 and 2013, the annual carbon uptake has been increasing by $5.8 \%$ per year on average, slightly faster than process cement emissions over the same period (5.4\% per year; Fig. 2a). Using a bookkeeping model to estimate the carbon sink in established buildings and infrastructure each year, we estimate that a cumulative amount of $4.5 \mathrm{GtC}(2.8-7.5, p=0.05)$ has been sequestered by cement materials since 1930. The annual carbonation carbon sink increased from $0.10{\mathrm{GtC} \mathrm{yr}^{-}}^{-}$

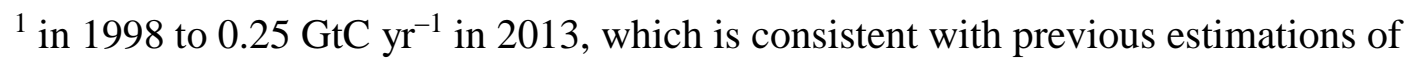

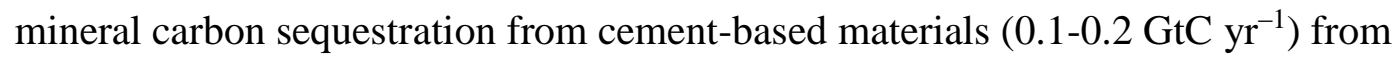


1926 to $2008^{7}$. In total, we estimate that roughly $43 \%$ of the cumulative cement process emissions of $\mathrm{CO}_{2}$ produced between 1930 and 2013 have been re-absorbed by carbonating cement materials, with an average of $44 \%$ of cement process emissions produced each year between 1980 and 2013 offset by the annual cement carbonation sink (Fig. 2b).

Figure 3 traces the cumulative cement process $\mathrm{CO}_{2}$ emissions between 1930 and 2013 according to regional production and use of cement in different materials, and to the life cycle of each type of materials. In the case of concrete, an average of $16.1 \%$ of the initial emissions are absorbed during the service life of the material, with an additional $1.4 \%$ being absorbed during the demolition of cement structures and another $0.1 \%$ absorbed during the disposal or re-use of the concrete waste. In the case of mortar cement, an average of $97.9 \%$ of the annual initial emissions is absorbed during the material's service life and the remaining $2.1 \%$ is absorbed in demolition stage (Fig. 3). Given expected demolition, waste disposal, and re-use of cement materials from the large amount of concrete structures and infrastructure built in the past half century, and the still-increasing cement consumption in China and other developing countries, the carbon sink of cement materials can be anticipated to increase in the future.

Although the Intergovernmental Panel on Climate Change (IPCC) Guidelines for National Greenhouse Gas Inventories provides methods for quantifying $\mathrm{CO}_{2}$ emissions during cement production process, they do not consider carbon absorbed by carbonation of cement materials. Furthermore, the rate of sequestration by 
carbonating cement is increasing rapidly (by an average of $5.8 \%$ per year during the period 1990-2013) as the stock of cement buildings and infrastructure increases, ages and gets demolished and disposed. The overall size of the cement sink between 1930 and 2013 is significant for the global carbon cycle. We estimate that the global carbon uptake by carbonating cement materials in 2013 was approximately $2.5 \%$ of the global $\mathrm{CO}_{2}$ emissions from all industrial processes and fossil fuel combustion in the same year ${ }^{2}$, which is equivalent to $22.7 \%$ of the average net global forest sink from 1990 to $2007^{26}$. The cement carbon sink of China alone in 2013 was about $0.14 \mathrm{GtC}$ year $^{-1}$, which accounts for $54 \%$ to $74 \%$ of the average net annual carbon sink in terrestrial ecosystems during the $1980 \mathrm{~s}$ and $1990 \mathrm{~s}^{27}$.

It is well-known that the weathering of carbonate and silicate materials removes $\mathrm{CO}_{2}$ from the atmosphere on geological time scales $\left(10^{4} \text { years }\right)^{28}$. However, the potential for removal by the weathering of cement materials has only recently been recognized ${ }^{29}$. Our results indicate that such enhanced weathering is already occurring on a large scale; existing cement stocks worldwide sequester approximately 1 billion tons of atmospheric $\mathrm{CO}_{2}$ each year. Future emissions inventories and carbon budgets may be improved by including this cement sink. Moreover, efforts to mitigate $\mathrm{CO}_{2}$ emissions should prioritize the reduction of fossil fuel emissions over cement process emissions given that produced cement entails creation of concomitant carbon sink. Indeed, if carbon capture and storage technology were applied to cement process emissions, the produced cements might represent a source of negative $\mathrm{CO}_{2}$ emissions ${ }^{30}$. Finally, policymakers might productively investigate ways to increase 
the completeness and rate of carbonation of cement waste (e.g., as a part of an enhanced weathering scheme $)^{31}$ to further reduce the climate impacts of cement emissions. 


\section{References}

$1 \quad$ USGS. Cement Statistics and Information.

http://minerals.usgs.gov/minerals/pubs/commodity/cement/index.html (2015).

2 Boden, T. A., Marland, G. \& Andres, R. J. Global, Regional, and National Fossil-Fuel $\mathrm{CO}_{2}$ Emissions. (Carbon Dioxide Information Analysis Center, 2014).

3 IEA. $\mathrm{CO}_{2}$ emissions from fuel combustion. (International Energy Agency, 2014).

4 Barcelo, L., Kline, J., Walenta, G. \& Gartner, E. Cement and carbon emissions. Mater. Struct. 47, 1055-1065 (2014).

5 Pade, C. \& Guimaraes, M. The $\mathrm{CO}_{2}$ uptake of concrete in a 100 year perspective. Cement. Concrete. Res. 37, 1348-1356 (2007).

6 Huntzinger, D. N., Gierke, J. S., Kawatra, S. K., Eisele, T. C. \& Sutter, L. L. Carbon dioxide sequestration in cement kiln dust through mineral carbonation. Environ. Sci. Technoly. 43, 1986-1992 (2009).

7 Renforth, P., Washbourne, C. L., Taylder, J. \& Manning, D. Silicate production and availability for mineral carbonation. Environ. Sci. Technol. 45, 2035-2041 (2011).

8 Johannesson, B. \& Utgenannt, P. Microstructural changes caused by carbonation of cement mortar. Cem. Concr. Res. 31, 925-931 (2001).

9 Papadakis, V. G., Vayenas, C. G. \& Fardis, M. N. Experimental investigation and mathematical modeling of the concrete carbonation problem. Chem. Eng. Sci. 46, 1333-1338 (1991).

10 Gajda, J. Absorption of atmospheric carbon dioxide by portland cement concrete. PCA $R \& D$ Serial (2001).

11 Andersson, R., Fridh, K., Stripple, H. \& Häglund, M. Calculating CO2 uptake for existing concrete structures during and after service life. Environ. Sci. Technol. 47, 11625-11633 (2013).

12 Dodoo, A., Gustavsson, L. \& Sathre, R. Carbon implications of end-of-life management of building materials. Resour. Conserv. Recy. 53, 276-286 (2009).

13 Engelsen, C. J., Mehus, J., Pade, C. \& Sæther, D. H. Carbon dioxide uptake in demolished and crushed concrete. Norwegian Building Research Institute, www. byggforsk. no, ISBN, 82-536 (2005).

14 Yoon, I.-S., Çopuroğlu, O. \& Park, K.-B. Effect of global climatic change on carbonation progress of concrete. Atmos. Environ. 41, 7274-7285 (2007). 

coefficient in open air concrete structures. Constr. Build. Mater. 29, 263-269 (2012).

Hu, M., Bergsdal, H., van der Voet, E., Huppes, G. \& Müller, D. B. Dynamics of urban and rural housing stocks in China. Build. Res. Inf. 38, 301-317 (2010).

Kapur, A., Keoleian, G., Kendall, A. \& Kesler, S. E. Dynamic Modeling of In - Use Cement Stocks in the United States. J. Ind. Ecol. 12, 539-556 (2008).

Yang, K.-H., Seo, E.-A. \& Tae, S.-H. Carbonation and CO2 uptake of concrete. Environ. Impact. Asses. 46, 43-52 (2014).

Galan, I., Andrade, C., Mora, P. \& Sanjuan, M. A. Sequestration of CO2 by concrete carbonation. Environ. Sci. Technol. 44, 3181-3186 (2010).

Silva, A., Neves, R. \& de Brito, J. Statistical modelling of carbonation in reinforced concrete. Cement Concrete Comp 50, 73-81 (2014).

Pommer, K., Pade, C., Institut, D. T. \& Centre, N. I. Guidelines: Uptake of Carbon Dioxide in the Life Cycle Inventory of Concrete. (Nordic Innovation Centre, 2006).

Kelly, T. D. Crushed Cement Concrete Substitution for Construction Aggregates, a Materials Flow Analysis. (US Department of the Interior, US Geological Survey, 1998).

Lutz, H. \& Bayer, R. Dry mortars. Ullmann's encyclopedia of industrial chemistry (2010).

Bossink, B. \& Brouwers, H. Construction waste: quantification and source evaluation. $J$. Constr. Eng. M. Asce. 122, 55-60 (1996).

Khanna, O. S. Characterization and Utilization of Cement Kiln Dusts (CKDs) as Partial Replacements of Portland Cement, University of Toronto, (2009).

Pan, Y. et al. A large and persistent carbon sink in the world's forests. Science 333, 988-993 (2011).

Piao, S. et al. The carbon balance of terrestrial ecosystems in China. Nature 458, 1009-1013 (2009).

Berner, R. A., Lasaga, A. C. \& Garrels, R. M. The carbon-silicate geochemical cycle and its effect on atmospheric carbon dioxide over the past 100 million years. AM. J. SCI. 283, 641683 (1983). emissions using accelerated weathering of limestone. Energy 32, 1471-1477 (2007). 
Supplementary Information is available in the online version of the paper

Competing financial interests The authors declare no competing financial interests.

\section{Author contributions}

F.X. and Z.L. designed the paper. F.X. conceived the research. F.X., C.P., T.S., J.W., K.H.Y., B.L., I.G., C.A. and P.C. provided the data from different countries and regions. T.S., F.X., J.W. and Y.Z. provided the survey statistics and experimental measurements data. S.J.D., F.X., Z.L., P.C., M.S. and D.G. performed the analysis. C.P., J.L., Z.L., L.J., P.C., K.H.Y., B.L., I.G., and Y.Z. provided the reference data. F.X., B.L., D.C.G., Z.L. M.D., L.Z. and M.S. performed uncertainty analysis. S.J.D. and B.L. drew the figures. All authors contributed to writing the paper.

Corresponding Author: Zhu Liu (zhuliu@caltech.edu).

Acknowledgments: Supported by the NSFC (41473076, 41501605, 51578344, 31100346), Fund of Youth Innovation Promotion Association CAS, Fund of Fellowships for Young International Distinguished Scientists in IAE, CAS. 

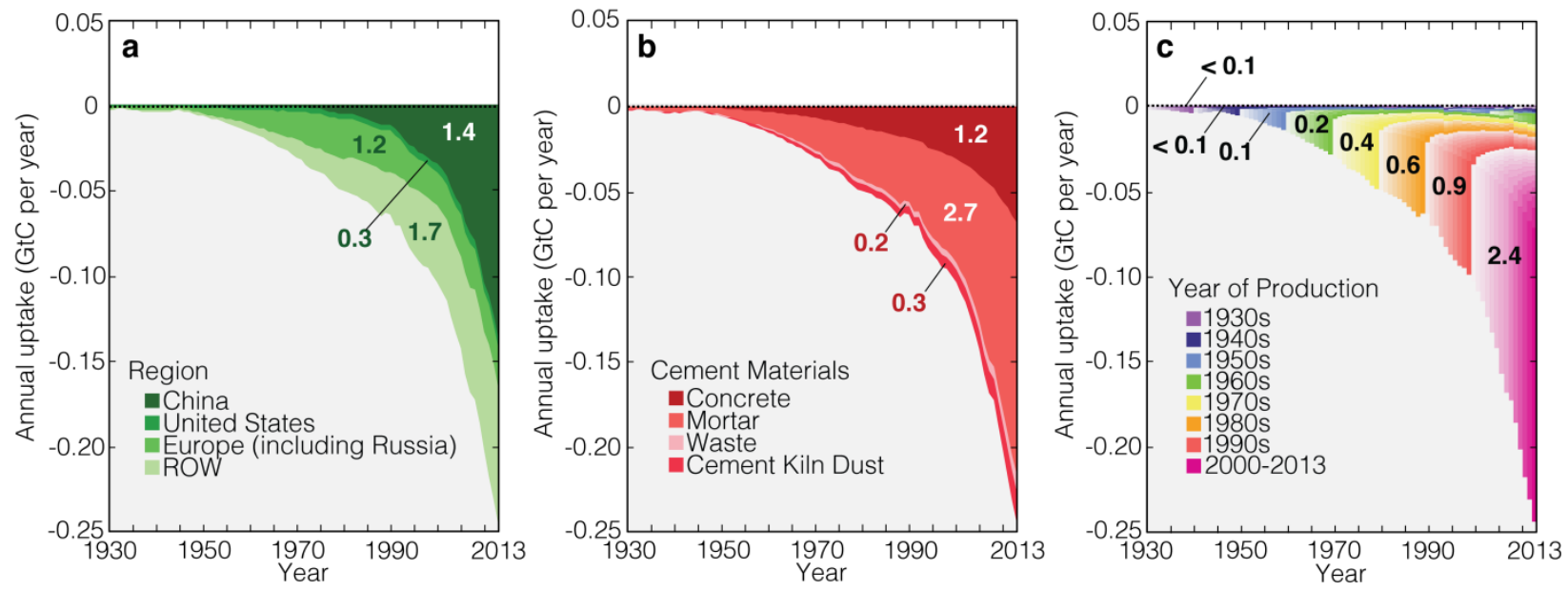

Figure 1 | Annual carbon sequestration by cement 1930-2013. Worldwide annual uptake of atmospheric $\mathrm{CO}_{2}$ by cement disaggregated by regions (a), by cement materials (b), and by years of which the cement produced $(\mathbf{c})$. The numbers in each panel indicate the cumulative carbon sequestration (median values from our uncertainty analysis). 


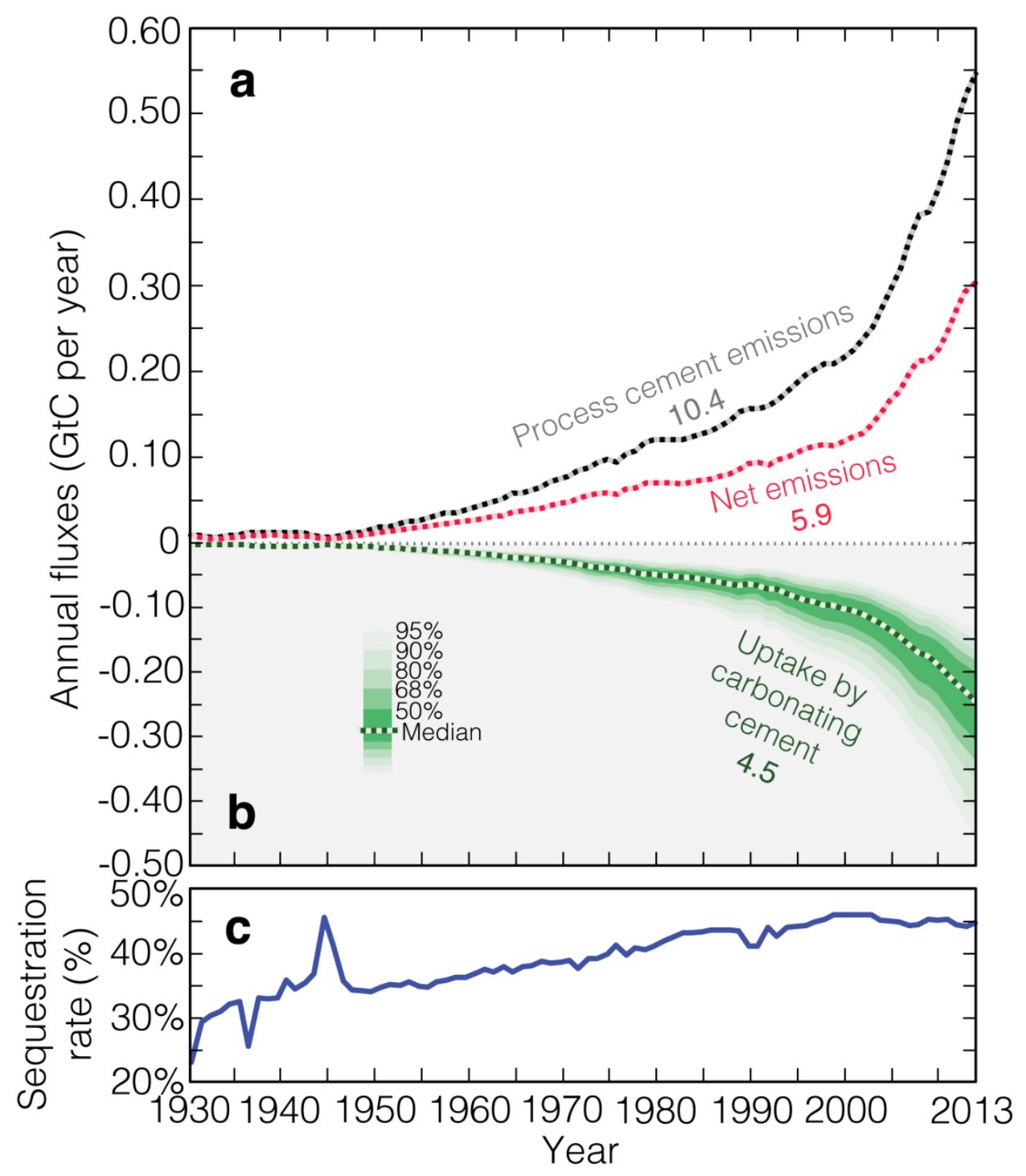

Figure 2 | Net cement emissions and annual sequestration rate 1930-2013.

Between 1930 and 2013, $10.4 \mathrm{GtC}$ was emitted by the cement industrial process ${ }^{2}$ (dashed black line, a). Over the same period, however, carbonating cements absorbed 4.5 GtC (2.8-7.5 GtC, $p=0.05$, green lines, $\mathbf{a})$, or $43 \%$ of the cumulative cement emissions. Existing cement is thus a large and overlooked carbon sink, sequestering roughly 44\% of cement emissions each year since 1980 (b). 


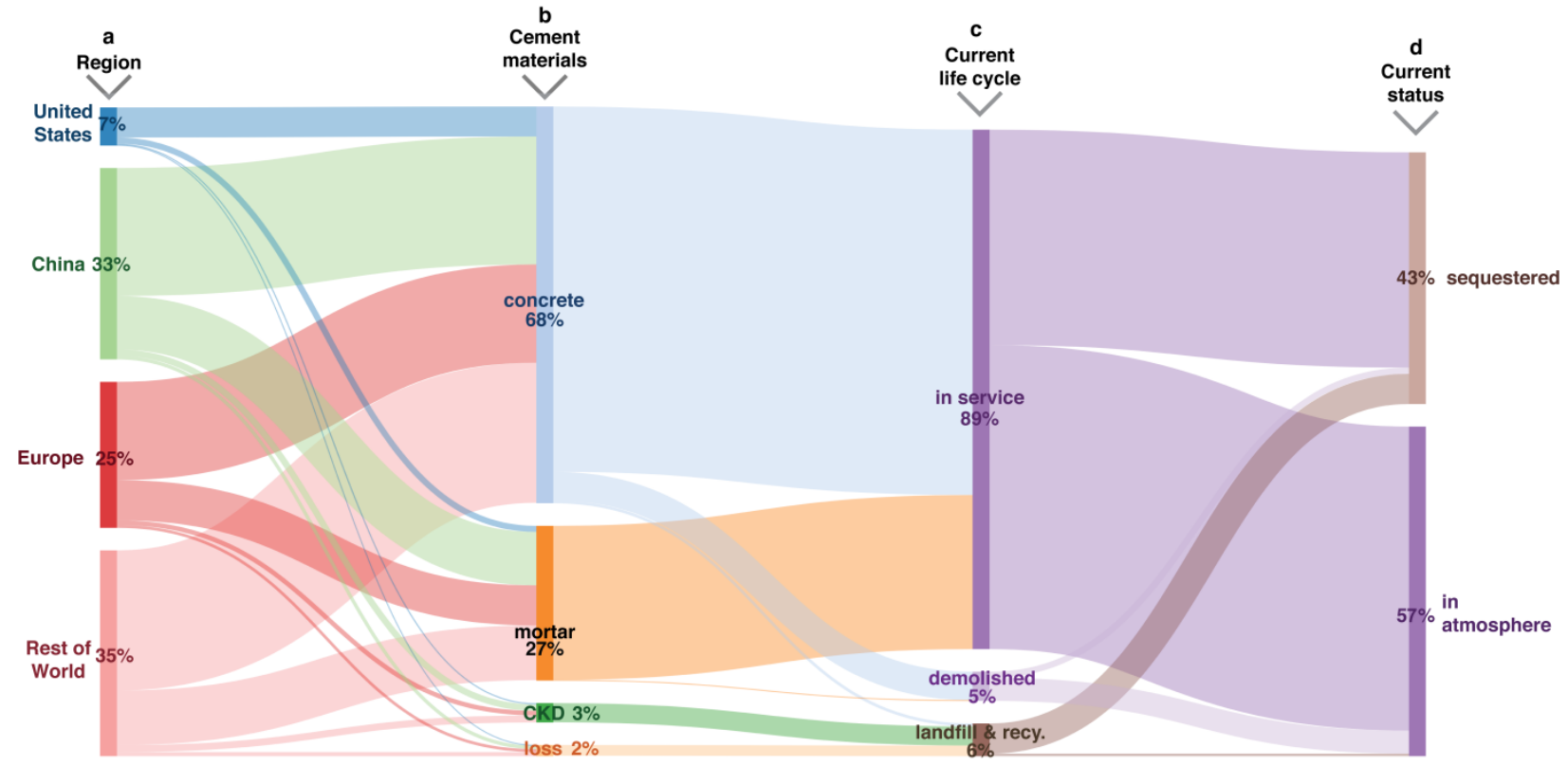

Figure 3 | Allocations of global historical cement process emissions 1930-2013.

Between 1930 and 2013, 7\%, 33\%, 25\% and 35\% carbon dioxide emissions from cement production are from United States, China, Europe, and rest of world, respectively (Region). The emissions are 69\% from concrete, $27 \%$ from mortar, $2 \%$ from loss cement in construction stage, and 3\% from CKD generation (Cement Materials). The emissions are $89 \%$ in service life cement, $5 \%$ attributed to demolished cement, and $6 \%$ attributed to demolition cement landfill and recycling (Current Life Cycle). The emissions are $43 \%$ are sequestered by cement materials and $57 \%$ are remaining in atmosphere (Current Status). 


\section{Methods}

\section{Global carbon uptake by cement carbonation}

Fengming Xi et al.

\section{Methods}

\section{Cement material carbonation}

Civil engineers use the term 'carbonation' to describe a complicated physicochemical reaction between $\mathrm{CO}_{2}$ and hydrated cement products in the presence of pore water, which ultimately sequesters carbon in cement material $1{ }^{15,32}$. In solution of pore water, $\mathrm{CO}_{2}$ reacts with $\mathrm{Ca}(\mathrm{OH})_{2}$, and in turn reacts with calcium silicate, dicalcium silicate, tricalcium silicate, tricalcium aluminate and other hydrated products. The carbonation reactions start at the surface of the cement or concrete and move inwards over time $e^{10,33}$. The main chemical reactions of carbonation are as follows:

$$
\begin{aligned}
& \mathrm{Ca}(\mathrm{OH})_{2}+\mathrm{CO}_{2} \stackrel{\mathrm{H}_{2} \mathrm{O}}{\longrightarrow} \mathrm{CaCO}_{3}+\mathrm{H}_{2} \mathrm{O} \\
& \left(3 \mathrm{CaO} \cdot 2 \mathrm{SiO}_{2} \cdot 3 \mathrm{H}_{2} \mathrm{O}\right)+3 \mathrm{CO}_{2} \stackrel{\mathrm{H}_{2} \mathrm{O}}{\longrightarrow} 3 \mathrm{CaCO}_{3} \cdot 2 \mathrm{SiO}_{2} \cdot 3 \mathrm{H}_{2} \mathrm{O} \\
& \left(2 \mathrm{CaO} \cdot \mathrm{SiO}_{2}\right)+2 \mathrm{CO}_{2}+x \mathrm{H}_{2} \mathrm{O} \stackrel{\mathrm{H}_{2} \mathrm{O}}{\longrightarrow} 2 \mathrm{CaCO}_{3}+\mathrm{SiO}_{2} \cdot x \mathrm{H}_{2} \mathrm{O} \\
& \left(3 \mathrm{CaO} \cdot \mathrm{SiO}_{2}+\mathrm{SO}_{2}+x \mathrm{H} Q \stackrel{\mathrm{H}_{2} \mathrm{O}}{\longrightarrow} \mathrm{CaCO}+\frac{1}{3} \mathrm{SiO} \cdot \underset{2}{x} \mathrm{HO}\right. \\
& \left(3 \mathrm{CaO} \cdot \mathrm{Al}_{2} \mathrm{O}_{3} \cdot \mathrm{HH} \mathrm{Q} \gg \mathrm{COO} \frac{\mathrm{H}_{2} \mathrm{O}}{2} \mathrm{AROH}\right)+{ }_{3} \mathrm{C} \mathrm{COa}+{ }_{3} \mathrm{HOB}
\end{aligned}
$$

\section{Process model of cement carbonation}

A life cycle assessment (LCA) method is used to estimate carbon uptake by cement materials over time (see supplementary information). Total carbon uptake of cement $\left(C_{u}\right)$ is calculated:

$$
C_{u}=\sum C o n+\sum M o r+\sum W a s t e+\sum C K D \quad[\text { eq. 1] }
$$

$\sum$ Con : carbon uptake by concrete cement.

$\sum$ Mor : carbon uptake by mortar cement.

$\sum$ Waste : carbon uptake by construction cement waste. 
$\sum C K D:$ carbon uptake by cement kiln dust (CKD).

\subsection{Carbon uptake by concrete cement}

The concrete life cycle divided into three phases: service life (e.g., in buildings), demolition, and secondary use (including both disposal in a landfill and recycling) ${ }^{5}$. In case, we calculate $\mathrm{CO}_{2}$ uptake as

$$
\sum \text { Con }=C_{l}^{t_{l}}+C_{d}^{t_{d}}+C_{s}^{t_{s}} \quad[\text { eq. 2] }
$$

$C_{l}^{t_{l}}:$ carbon uptake during the service life.

$C_{d}^{t_{d}}$ : carbon uptake during the demolition.

$C_{s}^{t_{s}}:$ carbon uptake during the secondary use stage.

\subsubsection{Service life}

\section{$\underline{\text { Concrete categories }}$}

We further break down cement utilization for different categories of concrete because the details of structure category are important for assessing strength class, cement content, exposure condition, exposed surface area, and service life $\mathrm{e}^{5,10,34-36}$.

\section{Concrete strength classes}

The strength classes of concretes are estimated based on the survey statistics and previous studies in US ${ }^{37,38}$, European and rest of world ${ }^{39}$ and Nordic countries ${ }^{5}$.

\section{$\underline{\text { Concrete cement content }}$}

The cement content for concrete $\left(C_{i}\right)$ is the mass of cement used in one cubic meter of concrete $\left(\mathrm{kg} / \mathrm{m}^{3}\right)^{34,37,39-43}$.

\section{Exposure conditions, $\mathrm{CO}_{2}$ concentrations, and additives.}

We estimate carbon uptake under five different categories of exposure conditions: exposed, sheltered, indoors, wet, and buried ${ }^{5}$. Specifically, relative humidity, ambient $\mathrm{CO}_{2}$ concentration ${ }^{14,44}$, and additives have been shown to affect carbonation rate coefficients ${ }^{9}$. The 
range of applicable conditions are estimated based on the previously referenced, region-specific studies and survey statistics ${ }^{5,9,10,14}$.

\section{Coating and coverings}

Application of surface coating and coverings such as paints can reduce the rates of cement carbonation by $10-30 \%^{36,45}$. Based on previous studies ${ }^{46-50}$, we assess carbonation using carbonation correction coefficients meant to reflect the potential effects of coatings, including decreases in carbonation rates of up to $50 \%$ over the life cycle of concretes ${ }^{51,52}$.

\section{Concrete carbonation rates}

Based on our estimates of concrete category, cement content, exposure conditions, additives and coatings, we use relevant concrete carbonation rate coefficients from various region-specific references ${ }^{5,10,19}$. We further calculated concrete carbonation rate coefficients by considering the impacts of compressive strength class and exposure conditions $\left(\beta_{c \mathrm{sec}}\right)^{12}$, cement additives $\left(\beta_{a d}\right)^{36}, \mathrm{CO}_{2}$ concentration $\left(\beta_{\mathrm{CO}_{2}}\right)^{9,14}$, and coating and cover $\left(\beta_{C C}\right)^{47,53}$.

$$
k_{l i}=\beta_{c \sec } \times \beta_{a d} \times \beta_{\mathrm{CO}_{2}} \times \beta_{c c}^{5} \quad \text { [eq. 3] }
$$

\section{$\underline{\text { Service life duration }}$}

The concrete service life $\left(t_{l}\right)$, the duration of the demolition stage $\left(t_{d}\right)$, and the duration of the secondary use stage $\left(t_{s}\right)$ are provided based on the previous, region-specific references ${ }^{5,16-}$ 18,54 .

\section{Carbonation depth}

The applicable carbonation rate coefficients and exposure times are used to calculate the carbonation depth $\left(d_{i}\right)$ of concrete in each strength class and set of exposure conditions using Fick's diffusion law (eq. 4$)^{5}$, where $k_{l i}$ is carbonation rate coefficient of concrete in strength class $i$ and $t_{l}$ is the time of service life in years:

$$
\left.d_{i}=k_{l i} \times \sqrt{t_{l}} \quad \text { [eq. } 4\right]
$$

\section{Exposed surface area}

The exposed surface area $\left(A_{i}\right)$ of concrete in the U.S., China, Europe, and other countries based on average thickness of concrete structures are listed in the literature ${ }^{5,10,21}$. 
Volume of carbonated concrete in service life

The carbonated concrete volume $V_{i}$ calculated as

$$
V_{i}=d_{i} \times A_{i} \quad \text { [eq. 5], }
$$

where $A_{i}$ is exposed surface area, $d_{i}$ represents the product of carbonation rate coefficient and carbonation depth for each concrete strength class $i$.

The carbonated cement in service life $\left(W_{l i}\right)$ can then be calculated as,

$$
W_{l i}=\sum_{i=1}^{n} V_{i} \times C_{i} \quad \text { [eq. 6] }
$$

where $C_{i}$ is the cement content of concrete in different strength classes $\left(\mathrm{kg} \text { cement } / \mathrm{m}^{3}\right)^{34,37,39-}$ ${ }^{43}$. Next, we calculate the cumulative carbon uptake of carbonated concrete in service life $\left(C_{l}^{t_{l}}\right.$ )

$$
C_{l}^{t_{l}}=W_{l} \times C_{c l i n \mathrm{ker}} \times f_{\mathrm{CaO}} \times \gamma \times M_{r} \quad \text { [eq. 7] }
$$

where $C_{\text {clinker }}$ is clinker to cement ratio ranged from $75 \%$ to $97 \%$ according to IPCC guidelines of 1997 and 2006, $f_{\mathrm{CaO}}$ is average $\mathrm{CaO}$ content of clinker in cement $(65 \%$, ranging from $60 \%$ to $67 \%)^{55}, \quad \gamma$ is the proportion of $\mathrm{CaO}$ within fully carbonated cement that converts to $\mathrm{CaCO}_{3}\left(0.80\right.$, ranging from 0.50 and $\left.1.00^{5,10-12,56,57}\right)$, and $M_{r}$ is the ratio of $\mathrm{C}$ element to $\mathrm{CaO}$ (a constant equal to the molar fraction in $\left.\frac{\mathrm{CO}_{2}}{\mathrm{CaO}} \times \frac{\mathrm{C}}{\mathrm{CO}_{2}}, 0.214\right)^{5}$.

The $C_{\text {clinker }}, f_{C a O}$, and $M_{r}$ in following Eqs [eq. 13], [eq. 21], [eq. 26], [eq. 29],[eq. 32], and [eq. 33] are same as [eq. 7].

\section{Annual carbon uptake by concrete in service}

Finally, we combine the results of the above calculations to calculate the annual carbon uptake in year $t_{l}\left(\Delta C_{l}^{t_{l}}\right)$ as the cumulative carbon uptake in year $t_{l}$ minus the cumulative carbon uptake in year $t_{l}-1$ :

$$
\Delta C_{l}^{t_{l}}=\sum C_{l}^{t_{l}}-\sum C_{l}^{\left(t_{l}-1\right)} \quad \text { [eq. 8] }
$$




\subsubsection{Demolition stage}

During demolition, concrete structures are crushed into smaller pieces so that contained steel reinforcing can be recycled and the concrete can be more easily transported. The fate of demolition waste in different regions is taken from different sources in the literatures. In China, sources suggest that more than $97 \%$ of concrete waste is landfilled, with less than $3 \%$ recycled $^{58}$. In contrast, roughly $60 \%$ of concrete is recycled in the U.S., with the remaining $40 \%$ sent to landfills ${ }^{17,22}$. Recycling rates are even higher in Europe, with data showing that $61.1 \%$ recycled and only $38.9 \%$ was sent to landfill ${ }^{5,21}$. Other studies indicate that recycling rates in rest of world are quite low: about $25 \%{ }^{18,59}$.

\section{Size and surface area of waste concrete pieces}

The surface area of concrete pieces after demolition is difficult to estimate. We use available data to estimate a range and particle size distribution of different types of demolished concrete in each region ${ }^{59,60}$.

\section{Exposure time}

We estimate the average exposure time $\left(t_{d}\right)$ of concrete during the demolition stage is about 0.4 years in the whole world ${ }^{5,11-13}$. Almost all these demolished and crushed concrete pieces are exposed to open air; only very small proportions are stockpiled under shelter ${ }^{12,59}$.

\section{Carbonation of demolished concrete}

We estimate the proportion $\left(F_{d i}\right)$ of concrete that will be carbonated during the demolition stage by assuming the shape of concrete particles and pieces is spherical ${ }^{21}$. The carbonation fraction is calculated according to particle size distributions and carbonation depths using the Fick's diffusion law:

$$
\begin{gathered}
D_{0 i}=2 d_{d i}=2 k_{d i} \times \sqrt{t_{d}} \\
F_{d i}= \begin{cases}100 \%-\int_{a}^{b} \frac{\pi}{6}\left(D-D_{0 i}\right)^{3} / \int_{a}^{b} \frac{\pi}{6} D^{3} * 100 \% & \left(\mathrm{a} \geq \mathrm{D}_{0 \mathrm{i}}\right) \\
100 \%-\int_{D_{0}}^{b} \frac{\pi}{6}\left(D-D_{0 i}\right)^{3} / \int_{a}^{b} \frac{\pi}{6} D^{3} * 100 \% & \left(\mathrm{a}<\mathrm{D}_{0 \mathrm{i}}<\mathrm{b}\right) \\
100 \% & \left(\mathrm{~b}<\mathrm{D}_{0 \mathrm{i}}\right)\end{cases} \\
\text { [eq. 10] }
\end{gathered}
$$

where $F_{d i}$ is the fraction of demolished concrete in strength class $i$ that is carbonated, $D_{0 i}$ is the maximum diameter of particles that undergo full carbonation in strength class $i, d_{d i}$ the 
carbonation depth of particles in strength class $i, k_{d i}$ is the carbonation coefficient of concrete in strength class $i$ in open air exposure conditions, $t_{d}$ is the average time for the demolition stage, $D$ is the diameter of demolished and crushed particles, $a$ and $b$ are the minimum and maximum diameter of crushed concrete particles in a given size distribution. All the particles less than $D_{0 i}$ will finish carbonation in $t_{d}$ years or less, such that $F_{d i}$ will be $100 \%$. For particle sizes larger than $D_{0 i}, F_{d i} \quad$ can be calculated by integration (eq. 10).

Using the fraction of concrete that will undergo carbonation for eq. 10, we next calculate the mass of concrete cement carbonated during the demolition stage $\left(W_{d}\right)$ as

$$
\begin{gathered}
W_{d i}=\left(W_{c i}-W\right)_{l} \times F \\
W_{d}=\sum_{i=1}^{n} W_{d}
\end{gathered}
$$

where $W_{d i}$ is the concrete cement carbonated during demolition for each concrete strength class $i, W_{c i}$ is the cement consumed for each strength class $i$ of concrete, $W_{l i}$ is the concrete cement carbonated during service life for each strength class $i$ ( $W_{l i}$ in eq. 6), $F_{d i}$ is the fraction of carbonated cement in concrete strength class $i$ in the demolition stage, and $W_{d}$ is the total mass of concrete cement carbonated in the demolition stage.

\section{Total carbon uptake during demolition stage}

Finally, we estimate total carbon uptake during the demolition stage $\left(C_{d}^{t_{d}}\right)$ based on cement carbonated in demolition stage and carbonation fraction of differently treated concretes:

$$
C_{d}^{t_{d}}=W_{d} \times C_{c \text { kierr }} \times f_{C} \mathrm{x}_{O} \times \Lambda \quad[\text { eq. 13] }
$$

$C_{d}^{t_{d}}$ is carbon uptake of concrete cement during demolition and $\gamma$ is the proportion of $\mathrm{CaO}$ within fully carbonated concrete that converts to $\mathrm{CaCO}_{3}$. The other parameters are same as [eq. 7].

\subsubsection{Secondary use stage}


After demolition, concrete materials continue to absorb carbon dioxide during secondary use stage. In sum, more than $91 \%$ of crushed concrete particles worldwide are buried, either in landfills or as part of their recycled use such as for road base or backfill aggregates ${ }^{13,18,22,58,59}$.

\section{Carbonation depth in secondary use stages}

The carbonation rate coefficients of waste concrete in the _secondary use stage will be slow and decreasing due to the layer of carbonated cement $\left(d_{d i}\right)$ that was during the demolition stage ${ }^{45}$ and the fact that most of the concrete is buried and not exposed to the air ${ }^{5}$. The total carbonation depth in demolition stage and secondary use stage $\left(d_{t i}\right)$ can be estimated by carbonated depth in demolition stage $\left(d_{d i}\right)$ plus new carbonation depth $\left(d_{s i}\right)$ during the secondary use stage. There is the time lag $\Delta t_{i}$ for the same carbonation depth $\left(d_{d i}\right)$ from air exposure condition to buried condition as follows:

$$
\begin{aligned}
& d_{d i}=K_{d i} \times \sqrt{t_{d i}}=K_{s i} \times \sqrt{t_{s i}} \\
& k_{d i} \times \sqrt{t_{d i}}=k_{s i} \times \sqrt{t_{s i}+\Delta t_{i}} \\
& \Delta t_{i}=t_{d i} \times\left(\frac{k_{d i}^{2}}{k_{s i}^{2}}-1\right)
\end{aligned}
$$

The total carbonation depth in demolition and secondary use stages $d_{t i}$ can then be calculated by

$$
d_{t i}=d_{d i}+d_{s i}=k_{s i} \times \sqrt{t_{s i}+t_{d i}+\Delta t_{i}} \quad \text { [eq. 17] }
$$

$d_{d i}$ : carbonation depth at the end of the demolition stage.

$k_{d i}$ : carbonation rate coefficient in the demolition stage (exposed to air).

$t_{d i}$ : carbonation time for existing carbonated depth $d_{d i}$ during demolition stage.

$k_{s i}$ : carbonation rate coefficient of concrete particle in strength class $i$ in secondary use stage (buried condition).

$t_{s i}$ : carbonation time for $d_{d i}$ if waste concrete in secondary use stage (buried condition). 
$\Delta t_{i}$ : time lag for the same carbonation depth $\left(d_{d i}\right)$ from buried condition to air exposure condition.

$d_{t i}$ : total carbonation depth in demolition stage and secondary use stage.

\section{Fraction carbonized}

The carbonation fraction of cement in concrete rubble $\left(F_{s i}\right)$ during the secondary use stage is calculated as:

$$
\begin{gathered}
D_{1 i}=2 d_{t i}=2 K_{s i} \times \sqrt{t_{s i}+t_{d i}+\Delta t_{i}} \\
F_{s i}= \begin{cases}100 \%-\int_{a}^{b} \frac{\pi}{6}\left(D-D_{t i}\right)^{3} / \int_{a}^{b} \frac{\pi}{6} D^{3} \times 100 \%-F_{d i} & \left(\mathrm{a} \geq \mathrm{D}_{1 \mathrm{i}}\right) \\
100 \%-\int_{D 1}^{b} \frac{\pi}{6}\left(D-D_{t i}\right)^{3} / \int_{a}^{b} \frac{\pi}{6} D^{3} \times 100 \%-F_{d i}\left(\mathrm{a}<\mathrm{D}_{1 \mathrm{i}}<\mathrm{b}\right) \\
100 \%-F_{d i} & \left(\mathrm{~b}<\mathrm{D}_{1 \mathrm{i}}\right)\end{cases}
\end{gathered}
$$

where $D_{1 i}$ is is the maximum diameter of particles that undergo full carbonation in strength class $i$ in demolition and secondary use stages, $D$ is the diameter of demolished and crushed particles, $F_{d i}$ is the fraction of carbonated waste concrete particle in strength class $i$ in the demolition stage, $a$ and $b$ are the minimum and maximum diameter of crushed concrete particles in a given size distribution. All the particles less than $D_{l i}$ will finish carbonation in $t_{s i}+t_{d i}+\Delta t_{i}$ years, so there $F_{s i}$ is $100 \%-F_{d i}$. The value of $F_{s i}$ for particle size larger than $D_{l i}$ can be calculated by integration.

\section{Cumulative and annual carbon uptake during the secondary use stage}

The cumulative and annual carbon uptake in the secondary use stage can be calculated by the following:

$$
\begin{gathered}
W_{s i}=W_{c i}-W_{l i}-W_{d i} \\
C_{s}^{t_{s}}=\left(\sum_{1}^{n} W_{s i} \times F_{s i}\right) \times C_{c l i n \mathrm{ker}} \times f_{C a O} \times \gamma \times M_{r}
\end{gathered}
$$




$$
\Delta C_{s}^{t_{s}}=C_{s}^{t_{s}}-C_{s}^{\left(t_{s}-1\right)}
$$

where $W_{s i}$ is the weight of cement used for strength class $i$ in secondary use stage, $W_{c i}$ is the weight of cement used for strength class $i$ in building construction stage, $W_{l i}$ is the carbonated concrete cement in strength class $i$ in service stage, $W_{d i}$ is carbonated concrete cement for concrete strength class $i$ in demolition stage, $F_{s i}$ is the fraction of carbonated strength class $i$ concrete cement in the treatment and secondary use stage, $\gamma$ is proportion of $\mathrm{CaO}$ within fully carbonated cement that converts $\mathrm{CaO}$ to $\mathrm{CaCO}_{3}, C_{s}^{t_{s}}$ is the cumulative carbon uptake in year $t_{s}$, and $C_{s}^{\left(t_{s}-1\right)}$ is the cumulative total carbon uptake in year $t_{s}-1, \Delta C_{s}^{t_{s}}$ is annual carbon uptake in year $t_{s}$ in secondary use stage. The other parameters are same as [eq. 7].

\subsection{Carbon uptake by mortar cement}

\subsubsection{Cement utilization for mortars}

Cement mortar is used for rendering and plastering (i.e. decorating), masonry (bricklaying), maintenance and repairing of concrete structures, and various other applications ${ }^{23,61,62}$. Most mortar is used for rendering, plastering and decorating ${ }^{61}$.

\subsubsection{The typical thickness of cement mortar utilization}

Rendering and plastering mortar is usually applied in a thickness of 10-30 mm and decorating (finishing) mortar is typically much thinner, only $1-5 \mathrm{~mm}^{23,61}$. When used as tile adhesive or grout, mortar is typically applied in thicknesses of $15-30 \mathrm{~mm}$ and $3-30 \mathrm{~mm}$, respectively $^{23}$. For self-leveling under layers, thicknesses vary from 5 to $30 \mathrm{~mm}$, and the thickness of mortar for screeds is 30 to $80 \mathrm{~mm}^{61,62}$. Most of these cement mortar thicknesses are about $20 \mathrm{~mm}^{23,33,45}$. The thickness of mortar for masonry is about $10 \mathrm{~mm}$, except for a small proportion in $2-3 \mathrm{~mm}$ for very even blocks ${ }^{23}$. Mortar used for maintaining and repairing (i.e. patching concrete structures and building surfaces) is applied similarly to rendering and adhesive uses, with mean thickness of $25 \mathrm{~mm}$.

\subsubsection{Carbonation rate coefficients of cement mortar}

Cement mortars have been shown to undergo carbonation at a faster rate than concrete ${ }^{63,64}$. The carbonation rate coefficients of cement mortar are between $6.1 \mathrm{~mm} / \sqrt{\text { year }}$ and 36.8 
$\mathrm{mm} / \sqrt{\text { year }}$ in outdoor and indoor exposure conditions, respectively (in temperate climate conditions and according to our field survey and experiment data using the $1 \%$ alcohol phenolphthalein solution). Carbonation depth will increase if the cement contain more additives $^{48}$. In this study, we use an average carbonation rate for mortar of $19.6 \mathrm{~mm} / \sqrt{\text { year }}$ but evaluate uptake assuming the full range $6.1 \mathrm{~mm} / \sqrt{\text { year }}$ and $36.8 \mathrm{~mm} / \sqrt{\text { year }}$.

\subsubsection{Carbon uptake by mortar cements}

We calculate annual carbon uptake based on the proportion of annual carbonation depth ${ }^{65}$, and estimate carbon uptake as the sum of uptake by rendering and plastering mortar $\left(C_{r p t}\right)$, uptake of masonry mortar $\left(C_{r m t}\right)$, and uptake of maintain and repairing mortar $\left(C_{r m a t}\right)$ :

$$
\sum M o r=C_{r p t}+C_{r m t}+C_{r m a t} \quad \text { [eq. 23] }
$$

Annual carbonation of cement in mortar used for rendering, plastering, and decorating is calculated by

$$
\begin{aligned}
& d_{r p}=K_{m} \times \sqrt{1} \\
& f_{r p t}=\left(d_{r p t}-d_{r p(t-1)}\right) / d_{T r p} \times 100 \% \\
& C_{r p t}=W_{m} \times r_{r p} \times f_{r p t} \times C_{c l i n \mathrm{ker}} \times f_{C a O} \times \gamma_{1} \times M_{r}
\end{aligned}
$$

where $d_{r p}$ is carbonation depth of rendering mortar, $K_{m}$ is the carbonation rate coefficient of cement mortar, $d_{r p t}$ and $d_{r p(t-1)}$ are the carbonation depths in $\mathrm{t}$ and (t-1) year, respectively, $d_{T r p}$ is the utilization thickness of rendering mortar, $f_{r p t}$ is the annual carbonation percentage of cement mortar for rendering, $C_{r p t}$ is the annual carbon uptake of carbonated mortar cement for rendering. $\gamma_{1}$ is the proportion of $\mathrm{CaO}$ within fully carbonated mortar cement that converts to $\mathrm{CaCO}_{3}, W_{m}$ is the cement for mortar and $r_{r p}$ is the percentage of cement for rendering in mortar cement . 
Carbon uptake of repairing and maintaining cement mortar

Annual carbon uptake of cement mortar for repairing and maintaining is calculated by

$$
\begin{aligned}
& d_{r m}=K_{m} \times \sqrt{t} \\
& f_{r m t}=\left(d_{r m t}-d_{r m(t-1)}\right) / d_{T r m} \times 100 \% \\
& C_{r m t}=W_{m} \times r_{r r} \times f_{r m t} \times C_{c l i n \mathrm{ker}} \times f_{C a O} \times \gamma_{1} \times M_{r}
\end{aligned}
$$

where $d_{r m}$ is the carbonation depth of repairing and maintaining mortar, $d_{r m t}$ and $d_{r m(t-1)}$ are the carbonation depths in $\mathrm{t}$ and ( $\mathrm{t}-1)$ year, respectively. $d_{T r m}$ is the utilization thickness of repairing and maintaining mortar. $f_{r m t}$ is the annual carbonation percentage of cement for repairing and maintaining mortar. $C_{r m t}$ is the annual carbon uptake of carbonated mortar cement for repairing and maintaining. $r_{r r}$ is the percentage of cement for repairing and maintaining in mortar cement. $\gamma_{1}$ is the proportion of $\mathrm{CaO}$ within fully carbonated mortar cement that converts to $\mathrm{CaCO}_{3}$,

The carbon uptake by masonry cement mortar can is calculated as

$$
C_{r m a t}=C_{m b t}+C_{m o t}+C_{m n t} \quad \text { [eq. 30] }
$$

where $C_{m b t}$ is carbon uptake by masonry mortar of walls with both sides rendered, $C_{m o t}$ is carbon uptake by masonry mortar of walls with one side rendered, and $C_{m n t}$ is carbon uptake by masonry mortar of walls with no rendering. The carbon uptake calculation method of $C_{m b t}$, $C_{m o t}$, and $C_{m n t}$ is similar as that of rendering and plastering mortar by considering wall thickness and demolition effects.

\subsection{Carbon uptake by cement in construction wastes}

We estimate carbon uptake of construction waste ${ }^{24,54}$ by

$$
\sum_{\text {waste }} \underset{\text { twastecto }}{ } C_{\text {w }}
$$




$$
\begin{aligned}
& C_{\text {wastecon }}=\left(\sum_{1}^{n} W_{c i} \times f_{\text {con }} \times r_{\text {cont }}\right) \times C_{\text {clin } \mathrm{ker}} \times f_{\text {CaO }} \times \gamma \times M_{r} \\
& C_{\text {wastemor }}=\left(\sum_{1}^{n} W_{m i} \times f_{\text {mor }} \times r_{\text {mor }}\right) \times C_{\text {clin } \mathrm{ker}} \times f_{C a O} \times \gamma_{1} \times M_{r}
\end{aligned}
$$

where $C_{\text {wastecon }}$ and $C_{\text {wastemor }}$ are carbon uptake by construction waste concrete and construction waste mortar, respectively. $W_{c i}$ is cement used for concrete in strength class i, $f_{\text {con }}$ is loss rate of cement for concrete in construction stage $\mathrm{e}^{24,40}, \quad r_{\text {cont }}$ is annual carbonation fraction of construction waste concrete, $\gamma$ is proportion of $\mathrm{CaO}$ within fully carbonated concrete that converts $\mathrm{CaO}$ to $\mathrm{CaCO}_{3}, \quad W_{m i}$ is cement used for mortar in strength class $\mathrm{i}$, $f_{\text {mor }}$ is loss rate of cement for mortar ${ }^{54,66}, \quad r_{\text {mor }}$ is annual carbonation fraction of construction waste mortar. $\gamma_{1}$ is the proportion of $\mathrm{CaO}$ within fully carbonated mortar cement that converts to $\mathrm{CaCO}_{3}$,

\subsection{Carbon uptake by cement kiln dust}

We estimate carbon uptake by CKD in different regions ${ }^{67-69}$ of the world based on the cement production, CKD generation rate, and proportion of CKD treatment in landfill (Supplementary Data 4) as follows:

$$
\sum_{C K D}=\left(\sum_{1}^{n} W_{i} \times C_{\text {clin } \mathrm{ker}} \times r_{C K D} \times r_{\text {landfill }}\right) \times f_{2_{C a O}} \times \gamma_{2} \times M_{r} \quad \text { [eq. 34] }
$$

where $W_{i}$ is the cement production in region i, $r_{C K D}$ is the CKD generation rate based on clinker $^{68}, \quad r_{\text {landfil }}$ is proportion of CKD treatment in landfill, $f_{2_{\text {caO }}}$ is $\mathrm{CaO}$ proportion in $\mathrm{CKD}^{70}$, and $\gamma_{2}$ is the fraction of $\mathrm{CaO}$ within fully carbonated $\mathrm{CKD}$ that has been converted to $\mathrm{CaCO}_{3}$.

\section{Uncertainty analysis}

We use a Monte Carlo method as recommended by the 2006 IPCC guidelines for National Greenhouse Gas Inventories to evaluate uncertainty of $\mathrm{CO}_{2}$ removal due to cement material carbonation $^{71}$. We identify 26 causes of uncertainties associated with carbon sequestration estimates which we vary across wide ranges to estimate the implications for carbon uptake (see 
Supplementary Information). The mean value carbon uptake from global cement materials is

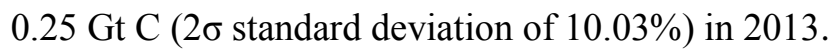

\section{Data Availability}

Data used in this research can be achieved in Supplementary Information. 
Papadakis, V. G., Vayenas, C. G. \& Fardis, M. A reaction engineering approach to the problem of concrete carbonation. AIChE Journal 35, 1639-1650 (1989).

Huang, N., Chang, J. \& Liang, M. Effect of plastering on the carbonation of a 35-year-old reinforced concrete building. Constr. Build. Mater. 29, 206-214 (2012).

Jonsson, G. \& Wallevik, O. Information on the use of concrete in Denmark, Sweden, Norway and Iceland. Icelandic Building Research Institute, www. ibri. is, ISBN, 9979-9174 (2005).

USGS. Nickel end-use statistics [through 2003; last modified September 1, 2005], in Kelly, T.D., and Matos, G.R., comps., Historical statistics for mineral and material commodities in the United States (2014 version): U.S. Geological Survey Data Series 140, 3 p (2014).

Lagerblad, B. Carbon Dioxide Uptake During Concrete Life Cycle: State of the Art.

(Swedish Cement and Concrete Research Institute, 2005).

Low, M.-S. Material flow analysis of concrete in the United States, Massachusetts Institute of Technology, (2005).

Nisbet, M. A. Environmental life cycle inventory of portland cement concrete. (Portland Cement Association Skokie, 2000).

ERMCO. (European Ready Mixed Concrete Organization) Ready-Mixed Concrete Industry Statistics 2001-2013, Available at (http://www.ermco.eu).

Zhou, H. Construction and Installation Engineering Budget Manual. (China Machine Press, 2003).

41 Huang, Z. \& Zhao, J. Concrete Mix Proportion Quick Manual. (China Building Industry Press, 2001).

Pommer, K. \& Pade, C. Guidelines: Uptake of Carbon Dioxide in the Life Cycle Inventory of Concrete. (Nordic Innovation Centre, 2006).

European_Committee_for_Standardization. in The European Standard EN 206- 1:2000

Concrete. Specification, performance, production and conformity (Brussel, 2001).

Talukdar, S., Banthia, N., Grace, J. \& Cohen, S. Carbonation in concrete infrastructure in the context of global climate change: Part 2-Canadian urban simulations. Cement Concrete Comp 34, 931-935 (2012).

Roy, S., Northwood, D. \& Poh, K. Effect of plastering on the carbonation of a 19-year-old reinforced concrete building. Constr. Build. Mater. 10, 267-272 (1996). 
Browner, R. Design prediction of the life for reinforced concrete in marine and other chloride environments. DURABILITY. BUILD. MAT. 1, 113-125 (1982).

Zhang, L. Carbonization delay coefficients research of concrete surface coverages. Journal of Xi'an Institute of Metallurgy \& Construction Engineering 21, 34-40 (in Chinese) (1989). applied to concrete for control of reinforcement corrosion. Constr. Build. Mater. 14, 55-59 (2000).

Zafeiropoulou, T., Rakanta, E. \& Batis, G. Performance evaluation of organic coatings against corrosion in reinforced cement mortars. Prog. Org. Coat. 72, 175-180 (2011). coated concrete for buildings. Constr. Build. Mater. 107, 299-306, (2016).

Moon, H. Y., Shin, D. G. \& Choi, D. S. Evaluation of the durability of mortar and concrete applied with inorganic coating material and surface treatment system. Constr. Build. Mater. 21, 362-369, (2007).

Papadakis, V. G. Effect of supplementary cementing materials on concrete resistance against carbonation and chloride ingress. Cem. Concr. Res. 30, 291-299 (2000).

54 Huang, T., Shi, F., Tanikawa, H., Fei, J. \& Han, J. Materials demand and environmental impact of buildings construction and demolition in China based on dynamic material flow analysis. Resour. Conserv. Recy. 72, 91-101, (2013).

Eggleston, S., Buendia, L. \& Miwa, K. 2006 IPCC guidelines for national greenhouse gas inventories: Volume 3 industrial processes and product use. (Kanagawa, JP: Institute for Global Environmental Strategies, 2006).

56 Takano, H. \& Matsunaga, T. CO2 fixation by artificial weathering of waste concrete and coccolithophorid algae cultures. Energy Convers. Manage. 36, 697-700 (1995).

57 Chang, C.-F. \& Chen, J.-W. The experimental investigation of concrete carbonation depth. Cem. Concr. Res. 36, 1760-1767 (2006).

58 Lu, W. Waste Recycling System Material Metabolism Analysis Model and Its Application Ph.D. thesis, Tsinghua University, (2010).

59 Kikuchi, T. \& Kuroda, Y. Carbon Dioxide Uptake in Demolished and Crushed Concrete. Journal of Advanced Concrete Technology 9, 115-124 (2011). 
HURCSQD. Beijing Local Standard - Technical Specifications for Application of Dry-mixed Mortar. DB11/T696-2009, J11582-12010 (Housing and Urban \& Rural Construction Standard Quota Division, 2010). (2001). the effects of hydraulicity and sand grain size on carbonation of lime and cement. Constr.

Build. Mater. 23, 1423-1428, (2009).

65 Jo, Y. K. Basic properties of epoxy cement mortars without hardener after outdoor exposure. Constr. Build. Mater. 22, 911-920 (2008). Lu, W. et al. An empirical investigation of construction and demolition waste generation rates in Shenzhen city, South China. Waste Manage. 31, 680-687 (2011).

Khanna, O. S. Characterization and utilization of cement kiln dusts (CKDs) as partial replacements of Portland cement, University of Toronto, (2009). Response, 1993).

Hawkins, G. J., Bhatty, J. I. \& O'Hare, A. T. in Innovations in Portland Cement Manufacturing (eds J.I Bhatty, F.M Miller, \& S.H Kosmatka) 735-779 (Portland Cement Association, 2004).

70 Sreekrishnavilasam, A., King, S. \& Santagata, M. Characterization of fresh and landfilled cement kiln dust for reuse in construction applications. Eng. Geol. 85, 165-173 (2006). greenhouse gas inventories. Institute for Global Environmental Strategies, Hayama, Japan (2006). 